\title{
Original Article \\ Emotional Intelligence of Pakistani Doctors and its relationship with Patient Doctor relationship
}

Syeda Shaista Waheed ${ }^{1}$, Tahir Siddique ${ }^{2}$

1 Professor, Department of Obstetrics \& Gynecology, Nawaz Sharif Medical College, Gujrat.

2 Professor of Medicine, Lahore General Hospital, Lahore

\section{ABSTRACT}

Introduction: Evaluation of impact of emotional intelligence (EI) of doctors on patient satisfaction could help in identifying areas of deficiencies in a particular organization. EI plays a pivotal role in successful medical practice. However, it is studied very less in Pakistani hospital environment for doctors as well as nursing staff. There is still lack of understanding about impact of EI on working of our health care system.

Objective: The aim of the study was to evaluate the emotional intelligence of resident doctors and its correlation with the satisfaction level of patients.

Methods: This study was done with post graduate residents (from first to fourth year). This was a correlational study conducted at Nawaz Sharif Medical College (NSMC), Gujrat for 6 months from March - August 2019. Sixty postgraduate residents took part in it. Convenient sampling was done, and prior permission was taken from ethical review board of NSMC. Anonymous Wong and Law Emotional Intelligence Scale (WLEIS) questionnaire was filled voluntarily by residents (self-rating) and by sister in charge (feedback). A patient feedback form was filled by the patients about the attending doctor to measure patient satisfaction level. Correlation between EI of doctors and patient satisfaction level was assessed. SPSS version 20 was used for data analysis. Correlation between EI and patient satisfaction level was calculated with application of paired sample $t$ test.

Results: The EI level of doctors rated by Nurse in charge's feedback was higher as compared to the one rated by self and positively correlated with patient doctor relationship. Higher score of EI is seen to be related with high patient satisfaction level. P value was $<0.01$ and $\mathrm{R}$ square value was 0.655 for correlation of EI (feedback) with patient satisfaction. Correlation of EI (self-rated) with patient satisfaction showed P value of 0.818 and $\mathrm{R}$ square value of 0.001 . Correlation between EI (Self-rated) and EI (feedback) was not statistically significant $(0.167)$ as calculated by pair sample $t$ test.

Conclusion: Higher scores of EI in doctors are positively correlated with patient satisfaction. EI of resident doctors calculated by feedback method is higher as compared to the one assessed by themselves.

Keywords: Emotional intelligence, Patient satisfaction, Feedback

doi: https://doi.org/10.53708/hpej.v3i1.206

This is an Open Access article and is licensed under a creative commons attribution (4.0 International License)

\section{INTRODUCTION}

Emotional intelligence plays a pivotal role in successful medical practice. However, it is studied very less in Pakistani hospital environment for doctors as well as nursing staff. Emotional intelligence is defined as "The ability to monitor one's own and other people emotions, to discriminate between different emotions, label them appropriately and to use emotional information to guide thinking and behavior" (Ravikumar et al., 2017). Emotional intelligence is a trait which makes a human distinct from the rest of the people with high cognitiveintelligence. It makes the plans successful and removes the hindrances in the pathway(Cao et al., 2017). It has nothing to do with the high intelligence quotient (IQ) score. It has been observed that people with high EI and low IQ are more courteous sympathetic and accommodating while those with high IQ and low EI are uncomfortable with people, less understanding and difficult to deal with (Kaur et al., 2015). Although a lot of emphasis is being placed on importance of emotional intelligence, there is still lack

Correspondence:

Dr. Syeda Shaista Waheed

Email address: shaistasyed28@hotmail.com,

Received: August 13, 2019 Accepted: November 24, 2019 of understanding about its whole impact on working of health care system (Bamberger et al., 2017).

Satisfaction of the patient is important component in developing trust over treating physician. Greater is the satisfaction; more improved is the clinical outcome (McKinley et al., 2015). The EI of the clinical doctors play a major role in developing a good relationship with patients. Important components affecting the patient doctor relationship are active listening to the patient complaints, understanding their problems, answering the queries of the patients and giving respect to the individuals. All these characteristics are basically part of emotional intelligence which is a type of non-cognitive intelligence (Shahid et al., 2016). There is limited research available showing association between patient satisfaction and emotional intelligence of doctors (Nightingale et al., 2018; Trivellas et al., 2013).

\section{METHODS}

The study was conducted in Gynecology department at Nawaz Sharif Medical College/Aziz Bhatti Shaheed Teaching Hospital, Gujrat. Approval was taken from Advanced Studies \& Research Board of Nawaz Sharif Medical College, Gujrat. Six months

Funding Source: Nil 
from March 2019 to August 2019. The residents were informed of the objectives and purpose of the study. They were assured of the confidentiality of the information provided and had an option of refusal to participate in the study. It was a descriptive correlation study. All the residents of Gynecology unit 1 and 2 were included in the study.

Questionnaire was distributed to the residents and nurse in charge by the college student section and it was not disclosed to anyone about the principal investigator who is conducting the research. All the residents were free to provide the response on voluntary basis. The pairing of data was done. The patient was giving response about the attending resident after 24-48 hours of her experience. The feedback about emotional intelligence status of that resident was filled by nurse in charge at the same time. The self-rating Performa of emotional intelligence was filled by resident her/himself and submitted back to the student's section. . The house officer on ward duty was assigned the responsibility to assist the patients in filling their response sheet and deposit it back to the concerned student section. Strict confidentiality was maintained during whole process.

All the postgraduate residents $\left(1^{\text {st }}-4^{\text {th }}\right.$ year $)$ working in Gynaecology department at ABSTH/Nawaz Sharif Medical College, Gujrat were included in the study. This included both male and female residents. All post graduate residents working in other departments of ABSTH/Nawaz Sharif Medical College, Gujrat were excluded.

Two questionnaires were used for data collection, including:

1. Wong and Law Emotional Intelligence questionnaire (WLEIS) to evaluate residents EI by self-assessment and feedback evaluation (Shi \& Wang, 2007).

2. Picker Patient Experience 15 Questionnaire (PPE 15), for evaluating patient satisfaction level. Both instruments have established validity and reliability (Baker et al., 2017).

As both scales used in the questionnaire have established validity and reliability, pilot study was conducted to address "understanding of item language" and "time taken to complete the questionnaire". The data from pilot study was not included in the results. An anonymous questionnaire was used to collect quantitative data so as to collect scores of two variables:

- Emotional intelligence of residents (self-assessment)

- Emotional intelligence of residents (feedback evaluation)

- Patient satisfaction level.

The objectives of the study were to compare the EI measured by self-assessment with that measured by feedback evaluation and to assess the relation between EI of residents and patient satisfaction level.

The Statistical Package for Social Science- (SPSS) 20 for Windows 10 was used for data entry and analysis. As data was collected through Liker Scale (continuous scale), parametric tests were applied. Data analysis was done through descriptive and inferential statistics. In the first step, a codebook was created for all the variables. The demographic data was presented using descriptive statistics for categorical variables (gender, age, year of training and residence) in the form of Frequency and Percentage. Descriptive statistics were also applied to calculate the range of scores obtained from WLEIS scale and PPE 15 scale. Correlational bivariate statistical test was applied to measure and describe the correlation between EI of residents and patient doctor relationship. For inferential statistics, Pearson productmoment correlation is applied when there are two continuous variables (Rumsey, 2011). Normality of the data was checked .Paired sample t test was applied to see the correlation between the EI scores taken by residents via self-rating and feedback method.

\section{RESULTS}

The results of demographic data were analyzed through descriptive statistics. As, demographic data was nominal, parametric tests were applied.

Table I: Demographic Characteristics

\begin{tabular}{|l|l|}
\hline \multicolumn{2}{|c|}{ Gender of Participants } \\
\hline Male Age & $3.4 \%$ \\
\hline Female & $96.6 \%$ \\
\hline \multicolumn{2}{|c|}{ Year of Training } \\
\hline $35-40$ years & $53.33 \%$ \\
\hline $30-34$ years & $33.33 \%$ \\
\hline $25-29$ years & $30 \%$ \\
\hline \multicolumn{2}{|c|}{} \\
\hline Fourth year trainees & $30 \%$ \\
\hline Third year trainees & $16.66 \%$ \\
\hline Second year trainees & $10 \%$ \\
\hline First year trainees & $75 \%$ \\
\hline \multicolumn{2}{|c|}{ Residence } \\
\hline Home & $25 \%$ \\
\hline Hostel &
\end{tabular}

Table II: Emotional Intelligence (Self-Rating)

\begin{tabular}{|l|c|c|c|}
\hline & N & Mean & SD \\
\hline SEA & 60 & 3.86 & 1.02 \\
\hline OEA & 60 & 3.87 & 1.02 \\
\hline UOE & 60 & 4.04 & 0.98 \\
\hline ROE & 60 & 3.20 & 1.37 \\
\hline EI & 60 & 3.74 & 0.79 \\
\hline Valid N & 60 & & \\
\hline
\end{tabular}

SEA-Self emotion appraisal, OEA---Other`s emotions appraisal UOE---Understanding of emotions, ROE---Regulation of emotions 
Table III: Emotional Intelligence of Residents (by self-rating) and Patient satisfaction Level

\begin{tabular}{|l|l|l|l|l|}
\hline & Mean & Mode & Standard Deviation & N \\
\hline Emotional Intelligence(by self-rating) & 3.74 & 4.06 & 0.79 & 60 \\
\hline Patient satisfaction Level & 1.17 & 1.02 & 0.14 & 60 \\
\hline
\end{tabular}

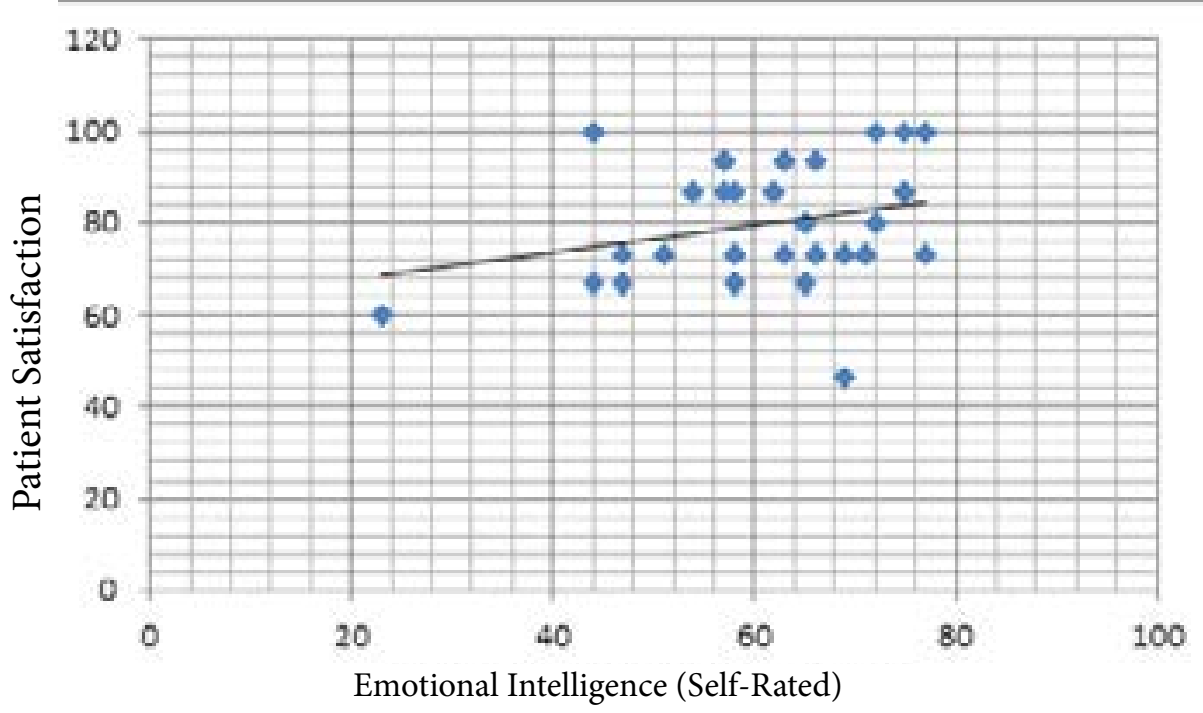

Fig. I Emotional Intelligence (Self-Rating)

The relationship between EI (self-rating) and patient satisfaction was insignificant as we found on calculating the correlation between EI (self-rated) and patient satisfaction level. P value was found to be 0.818 which is statistically insignificant. The mode value for EI by self-rating was 4.06 and for patient satisfaction was 1.02 .

For one unit change in EI (by self-rating) there is insignificant effect on patient satisfaction level because the $P$ value was found to be 0.818 which is not significant.(Fig 1) Pearson's correlation was calculated in order to determine the relationship between the emotional intelligence of resident doctors calculated on WLEIS by self-rating. $\mathrm{P}$ value is 0.818 which is practically insignificant. ( $\mathrm{r}=0.001, \mathrm{~N}=60, \mathrm{P}=0.818)$. $\mathrm{R}$ square value is 0.001 which means emotional intelligence of residents (by self-rating) is contributing to patient satisfaction level by $0.1 \%$ only.

Table IV: Emotional Intelligence (By Feedback)

\begin{tabular}{|l|c|c|c|}
\hline & N & Mean & SD \\
\hline SEA & 60 & 4.47 & 0.79 \\
\hline OEA & 60 & 4.34 & 0.67 \\
\hline UOE & 60 & 4.49 & 0.69 \\
\hline ROE & 60 & 4.32 & 0.63 \\
\hline EI & 60 & 4.40 & 0.60 \\
\hline Valid N & 60 & & \\
\hline
\end{tabular}

SEA-Self emotion appraisal, OEA-Other`s emotions appraisal
Table V: Emotional Intelligence of Residents (by feedback evaluation) and Patient satisfaction Level

\begin{tabular}{|l|c|c|c|c|}
\hline & Mean & Mode & $\begin{array}{c}\text { Standard } \\
\text { Deviation }\end{array}$ & $\mathrm{N}$ \\
\hline $\begin{array}{l}\text { Emotional } \\
\text { Intelligence }\end{array}$ & 4.40 & 4.75 & 0.60 & 60 \\
\hline $\begin{array}{l}\text { Patient } \\
\text { Satisfaction } \\
\text { Level }\end{array}$ & 1.18 & 1.02 & 0.14 & 60 \\
\hline
\end{tabular}

$\mathrm{R}$ square value is 0.655 which is significant. It means that $65 \%$ of the patient satisfaction is dependent on emotional intelligence level of the doctor (rated by feedback evaluation).

Pearson's correlation was calculated in order to determine the relationship between the emotional intelligence of resident doctors calculated on WLEIS by feedback evaluation. $P$ value is 0.000 which is highly significant as it is $<0.01(\mathrm{P}<0.05$ is significant and $\mathrm{P}<0.01$ is highly significant).

There is strongly positive correlation between EI of residents calculated by feedback evaluation and patient satisfaction level calculated by PPE $15(\mathrm{r}=0.655, \mathrm{~N}=60, \mathrm{P}=0.00)$. The Mode value for EI by feedback was 4.75 and for patient satisfaction was 1.02 (FIG 2). The values of EI (self-rated) and EI (feedback) are NOT correlated. The correlation is 0.167 but it is not significant statistically. This means that the doctor's own assessment of his/ her EI is not correlated with feedback assessment of his/her EI. So, a doctor may rate his EI low, but it doesn't mean the other could rate him/her high on EI score (Table VI).

UOE---Understanding of emotions, ROE--Regulation of 


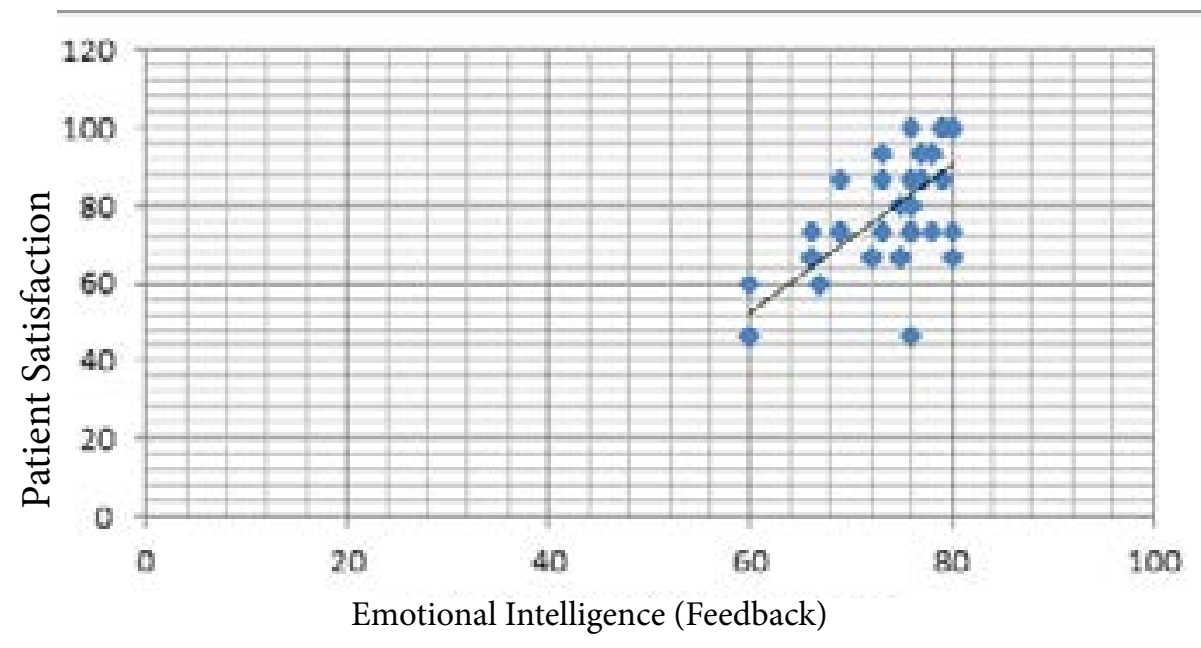

Fig. II Emotional Intelligence (By Feedback)

Table VI: Paired Samples Correlation of EI(Self-rated) \& EI(Feedback)

\begin{tabular}{|l|l|c|c|c|}
\hline & & N & Correlation & Significance \\
\hline Pair 1 & EI(Self-rated)\& EI(Feedback) & 60 & 0.167 & 0.203 \\
\hline
\end{tabular}

The difference in mean values of EI is statistically significant. (Table VII)

Table VII: Paired Samples t test

\section{Paired Samples Test}

\begin{tabular}{|c|c|c|c|c|c|c|c|c|c|}
\hline & & \multicolumn{5}{|c|}{ Paired Differences } & \multirow{3}{*}{$\mathrm{t}$} & \multirow{3}{*}{$\begin{array}{c}\text { df } \\
\text { (sample } \\
\text { size-1) }\end{array}$} & \multirow{3}{*}{ Sig. (2-tailed) } \\
\hline & & \multirow[t]{2}{*}{ Mean } & \multirow{2}{*}{$\begin{array}{l}\text { Std. Devia- } \\
\text { tion }\end{array}$} & \multirow{2}{*}{$\begin{array}{l}\text { Std. Error } \\
\text { Mean }\end{array}$} & \multicolumn{2}{|c|}{$\begin{array}{l}\text { 95\% Confidence Interval of the } \\
\text { Difference }\end{array}$} & & & \\
\hline & & & & & Lower & Upper & & & \\
\hline Pair 1 & EI1 - EI2 & -0.66 & 0.91 & 0.11 & -0.89 & -0.42 & -5.58 & 59 & 0.000 \\
\hline
\end{tabular}

\section{DISCUSSION}

Emotional intelligence is very important characteristic needed for the doctors who are interacting all the time with patients, families of patients, colleagues and paramedical staff. In our local culture, the duty doctors have certain additional responsibilities like management of the ward and leadership in addition to treatment of patients. In such situation, emotionally intelligent doctors are better able to deal with the situations arising at duty (Gregory et al., 2017; Hageman et al., 2015).

Focusing on the importance of emotional intelligence of doctors and its effects on patient satisfaction level, chapter five explains the study's findings and its comparison with previous studies, its limitations, future research and recommendations (Aldaod et al., 2019; Goleman, 1996, 1998). The emotional intelligence score of resident doctors of gynecology calculated by self-rating is lower (mean $=3.7469, \mathrm{SD}=0.798$ ) as compared to score of $\mathrm{EI}$ of resident doctors by feedback scoring done by sister in-charge $($ Mean $=4.40, \mathrm{SD}=0.60)$.

Regression analysis was done. Pearson's correlation was calculated. In this study, the emotional intelligence of residents rated by sister in-charge is having highly significant association with patient satisfaction level, $(\mathrm{r}=0.655, \mathrm{~N}=60, \mathrm{P}=0.00)$. $\mathrm{R}$ square value is 0.655 which is significant. It means that $65 \%$ of the patient satisfaction is dependent on emotional intelligence level of the doctor (rated by feedback evaluation).

In contrast the emotional intelligence rated by doctors themselves was having positive but very week association with patient satisfaction level, having $\mathrm{P}$ value of $0.818 \quad(\mathrm{r}=0.001$, $\mathrm{N}=60, \mathrm{P}=0.818$ ). $\mathrm{R}$ square value is 0.001 which means emotional intelligence of residents (by self-rating) is contributing to patient satisfaction level by $0.1 \%$ only. The mean value of EI by self-rating and by feedback method are 3.74 and 4.40 respectively which are lower than the mean EI score of 4.57 seen in workers by Law et al. (2004). Parker et al. also had similar results that feedback is more effective in assessing emotional intelligence and its effects on workplace environment then self-rating (Parker et al., 2011). In a study conducted by Dana L. Joseph, Daniel A. Newman it was seen that peer assessed emotional intelligence assessment is more relevant in terms of utility as compared to self-rating (Joseph \& Newman, 2010). Clive Fletcher,Caroline Baldry also stated that multi source evaluation is more helpful then selfrating in assessing EI but the rater bias is also important to assess 
and avoid (Fletcher \& Baldry, 2000). The results are comparable to the study conducted by Hui-Ching Weng et al in 2008 which showed that multisource feedback is more effective in predicting emotional intelligence of doctors then self-rating scores of EI (Weng et al., 2008).

The results are also comparable to the study done by Audrey Marie Beauvais et al which showed that high emotional intelligence and empathy in doctors lead to reduced burn out and high patient satisfaction status (Beauvais et al., 2017). The results are comparable to the study done by Stéphane Côté et al which concluded that EI assessed by peers is predictive of leadership qualities and non-cognitive characteristics. No significant association is seen when EI was assessed by selfrating (Côté et al., 2010). Beierle et al also experienced this that decrease in burnout was indirectly related to improvement in patient satisfaction level. This decrease in burnout is possible by improvement in EI of surgery residents. It is seen that changes in curriculum to improve EI could help decrease the chances of mistakes and improve patient satisfaction level (Beierle et al., 2019). In another study surgeon's emotional intelligence was highly related to patient satisfaction level (Celik, 2017). Goldzweig et al. concluded that actual quality of communication between physician and his patient is very essential for developing good patient doctor relationship. A physician with good know how of his emotional competencies could fulfill the demands of the patients better (Goldzweig et al., 2015). Andrea Pilkington et al stated that emotional intelligence is highly related to patient satisfaction level and improvement in the score of EI simultaneously enhance patient satisfaction and decrease litigation in obstetrics and gynecology (Pilkington et al., 2012). High EI is associated with high patient satisfaction with low litigation against the doctors and vice versa (Shouhed et al., 2019). Wright et al. stated that multisource evaluation is effective but should not be dependent on questionnaire response alone (Wright et al., 2012). Very similar to this study, Roberts et al. reported that the self-rating is having lower scores than rating by colleagues and patients, which has high scores for EI. The scoring is effected significantly by the rating person and the one who is rated (Roberts et al., 2013). This is probably depending on place of training and specialty but multisource feedback alone could not be used as a tool to judge the fitness of a doctor to practice medicine (Roberts et al., 2013; Wright et al., 2012).

Since obstetrics and gynecology is a specialty dealing with highly demanding circumstances for the staff as well as patients, emotional intelligence skills play important role in decision making and management of the patients. This is similar to the results seen for patient satisfaction in our study. Improvement in EI of residents of gynecology by focused interventions could reduce complaints in this specialty (Pilkington et al., 2012).

Like our study, EI is identified as an important quality of a practicing doctor to be successful and efficient. EI is a quality that can be taught. The areas which need to be focused to improve EI are empathy, firmness and sovereignty. Among the three, empathy is most important one. Also, no gender difference in EI was found (Shahid et al., 2016). Satterfield et al. in his study stated that EI has important impact on health, work environment and performance of the staff. EI has been linked positively to the patient satisfaction level which is comparable to our study (Satterfield et al., 2009).

In a study conducted by McKinley et al., EI of residents was having less standard deviation as compared to the general population. Certain strengths and weaknesses were seen in residents. The major weaknesses were in social awareness and flexibility mainly. Target oriented programs could result in improved EI. Higher EI score leads to better workplace performance and patient satisfaction level which is similar to the results seen in our study (McKinley et al., 2015).

The results of this study are also comparable to a study conducted by Bamberger et al. which showed that high level of EI score is associated with less burnout of residents. This ultimately improved patient satisfaction rate and performance at work place (Bamberger et al., 2017). Similar results showing association of decrease in burnout with high EI score leading to better performance at workplace and patient satisfaction are seen in many studies. However, a study conducted by Weng et al. showed contradictory results from our study. It showed that empathy is more strongly correlated with long term patient satisfaction as compared to EI which is having week association (Weng et al., 2008).

\section{Limitations}

The limitations of this study were.

1. First, the study was conducted in a single department of the institute. As obstetrics and gynecology environment is very demanding due to high patient turnover, less resources, deficient staff and complicated state of affairs of the patients, the role of EI needs to be addressed especially in our part of the world. So, its scope was restricted to Gynaecology department of Nawaz Sharif Medical College, Gujarat.

2. It can be extended to the residents of gynecology departments of other medical colleges of Punjab to see the wider picture.

3. As it was a correlational study, it only provides the snapshot of EI and its effect on patient satisfaction level. Therefore, further research with longitudinal design is required to gain insight into the understanding of residents regarding EI and patient doctor relationship.

4. Further studies including non-surgical specialties and basic sciences residents could provide further insight into the situation.

\section{Way Forward}

There are certain recommendations for future research.

1. As this study is done in single department, further studies could be done by involving gynecology departments of other hospitals and other clinical and non-clinical departments of this institute.

2. As emotional intelligence is a flexible and modifiable variable, interventional studies can be done to assess EI before intervention and to see the effect on EI of doctors as well as paramedical staff after intervention. This will 
help to assess the effect on workplace environment and performance.

3. In future studies it will be beneficial to compare EI scores of public and private hospitals of Pakistan. This can help to find the weak points at health care services. Correcting such weaknesses could definitely lead to enhanced work performance and improved client satisfaction.

\section{CONCLUSION}

The purpose of this correlational study was to assess the level of EI in resident doctors of gynecology by self-rating and feedback and to see the relationship of EI with patient satisfaction level. The EI score by self-rating is lesser then the EI score by feedback. This underrating of EI may be due to low confidence level, lower socioeconomic background, increase workload or poor emotional support at home or at workplace. EI scoring by feedback method is having highly significant and positive correlation with patient satisfaction level. This leads to development of good patient doctor relationship. Interventions such as workshops and seminars could be included in the residency programs to train the residents and improve EI in them. This will result in lesser mistakes and higher patient satisfaction resulting in better patient doctor relationship.

\section{DECLARATION OF INTEREST}

The authors report no declaration of interest.

\section{REFERENCES}

Aldaod, S. M., Sweis, R. J., Alawneh, A. R., \& Jaradat, M. (2019). Emotional intelligence effect in health sector: a literature review. International Journal of Information, Business and Management, 11(4), 08-94. https://search.proquest.com/openview/af2e04fdc4 5 e $465 \mathrm{cbd} 9473136 \mathrm{fe} 0 \mathrm{fb} 27 / 1$ ? pq-origsite $=$ gscholar $\& \mathrm{cbl}=2032142$

Baker, P., Tytler, B., Artley, A., Hamid, K., Paul, R., \& Eardley, W. (2017). The use of a validated pre-discharge questionnaire to improve the quality of patient experience of orthopaedic care. BMJ quality improvement reports, 6(1). https://doi.org/10.1136/ BMJQIR.W7046

Bamberger, E., Genizi, J., Kerem, N., Reuven-Lalung, A., Dolev, N., Srugo, I., \& Rofe, A. (2017). A pilot study of an emotional intelligence training intervention for a paediatric team. Archives of Disease in Childhood, 102(2), 159-164. https://doi. org/10.1136/archdischild-2016-310710

Beauvais, A., Andreychik, M., \& Henkel, L. A. (2017). The role of emotional intelligence and empathy in compassionate nursing care. Mindfulness \& Compassion, 2(2), 92-100. https://doi. org/10.1016/J.MINCOM.2017.09.001

Beierle, S. P., Kirkpatrick, B. A., Heidel, R. E., Russ, A., Ramshaw, B., McCallum, R. S., \& Lewis, J. M. (2019). Evaluating and exploring variations in surgical resident emotional intelligence and burnout. Journal of surgical education, 76(3), 628-636. https://doi.org/10.1016/j.jsurg.2018.11.004
Cao, W., Qi, X., Yao, T., Han, X., \& Feng, X. (2017). How doctors communicate the initial diagnosis of cancer matters: cancer disclosure and its relationship with Patients' hope and trust. Psycho-oncology, 26(5), 640-648. https://doi.org/10.1002/ pon. 4063

Celik, G. O. (2017). The relationship between patient satisfaction and emotional intelligence skills of nurses working in surgical clinics. Patient preference and adherence, 11, 1363. https://doi. org/10.2147/PPA.S136185

Côté, S., Lopes, P. N., Salovey, P., \& Miners, C. T. (2010). Emotional intelligence and leadership emergence in small groups. The Leadership Quarterly, 21(3), 496-508. https://doi. org/10.1016/J.leaqua.2010.03.012

Fletcher, C., \& Baldry, C. (2000). A study of individual differences and self-awareness in the context of multi-source feedback. Journal of Occupational and Organizational Psychology, 73(3), 303-319. https://doi.org/10.1348/096317900167047

Goldzweig, G., Abramovitch, A., Brenner, B., Perry, S., Peretz, T., \& Baider, L. (2015). Expectations and level of satisfaction of patients and their physicians: concordance and discrepancies. Psychosomatics, 56(5), 521-529. https://doi.org/10.1016/J. PSYM.2014.10.001

Goleman, D. (1996). Emotional intelligence. Why it can matter more than IQ. Learning, 24(6), 49-50.

Goleman, D. (1998). Working with emotional intelligence: Bantam.

Gregory, P. J., Robbins, B., Schwaitzberg, S. D., \& Harmon, L. (2017). Leadership development in a professional medical society using 360-degree survey feedback to assess emotional intelligence. Surgical Endoscopy, 31(9), 3565-3573. https://doi. org/10.1007/s00464-016-5386-8

Hageman, M. G., Ring, D. C., Gregory, P. J., Rubash, H. E., \& Harmon, L. (2015). Do 360-degree feedback survey results relate to patient satisfaction measures? Clinical Orthopaedics and Related Research ${ }^{\oplus}$, 473(5), 1590-1597. https://doi.org/10.1007/ s11999-014-3981-3

Joseph, D. L., \& Newman, D. A. (2010). Discriminant validity of self-reported emotional intelligence: A multitrait-multisource study. Educational and Psychological Measurement, 70(4), 672694. https://doi.org/10.1177/0013164409355700

Kaur, D., Sambasivan, M., \& Kumar, N. (2015). Impact of emotional intelligence and spiritual intelligence on the caring behavior of nurses: a dimension-level exploratory study among public hospitals in Malaysia. Applied Nursing Research, 28(4), 293-298. https://doi.org/10.1016/j.apnr.2015.01.006

Law, K. S., Wong, C.-S., \& Song, L. J. (2004). The construct and criterion validity of emotional intelligence and its potential utility for management studies. Journal of applied Psychology, 89(3), 483. . https://doi.org/10.1037/0021-9010.89.3.483 
McKinley, S. K., Petrusa, E. R., Fiedeldey-Van Dijk, C., Mullen, J. T., Smink, D. S., Scott-Vernaglia, S. E., Phitayakorn, R. (2015). A multi-institutional study of the emotional intelligence of resident physicians. The American Journal of Surgery, 209(1), 26-33. https://doi.org/10.1016/j.amjsurg.2014.09.015

Nightingale, S., Spiby, H., Sheen, K., \& Slade, P. (2018). The impact of emotional intelligence in health care professionals on caring behaviour towards patients in clinical and long-term care settings: Findings from an integrative review. International journal of nursing studies, 80, 106-117. https://doi.org/10.1016/j. ijnurstu.2018.01.006

Parker, J. D., Keefer, K. V., \& Wood, L. M. (2011). Toward a brief multidimensional assessment of emotional intelligence: Psychometric properties of the Emotional Quotient InventoryShort Form. Psychological Assessment, 23(3), 762. https://doi. org/10.1037/a0023289

Pilkington, A., Hart, J., \& Bundy, C. (2012). Training obstetricians and gynaecologists to be emotionally intelligent. Journal of Obstetrics and Gynaecology, 32(1), 10-13. https://doi.org/10.31 09/01443615.2011.623806. https://doi.org/10.3109/01443615.20 11.623806

Ravikumar, R., Rajoura, O., Sharma, R., \& Bhatia, M. S. (2017). A study of emotional intelligence among postgraduate medical students in Delhi. Cureus, 9(1). https:doi.org/⒑7759/ cureus.989

Roberts, M. J., Campbell, J. L., Richards, S. H., \& Wright, C. (2013). Self-Other Agreement in Multisource Feedback: The Influence of Doctor and Rater Group Characteristics. Journal of Continuing Education in the Health Professions, 33(1), 14-23. https://doi.org/10.1002/chp.21162

Rumsey, D. J. (2011). Statistics for dummies. Hoboken. NJ: John Wiley \& Sons. Sabina, C., Cuevas, CA, \& Schally, JL (2012). The cultural influences on help-seeking among a sample of victimized Latino women. American Journal of Community Psychology, 49, 347-363. https://doi.org/10.1007/s10464-0119462-x
Satterfield, J., Swenson, S., \& Rabow, M. (2009). Emotional intelligence in internal medicine residents: Educational implications for clinical performance and burnout. Annals of behavioral science and medical education: journal of the Association for the Behavioral Sciences and Medical Education, $14(2), 65$.

Shahid, R., Stirling, J., \& Adams, W. (2016). Assessment of emotional intelligence in pediatric and med-peds residents. Journal of Contemporary Medical Education, 4(4), 153-158. https://doi.org/10.5455/jcme.20170116015415

Shi, J., \&Wang, L. (2007). Validation of emotional intelligence scale in Chinese university students. Personality and Individual Differences, 43(2), 377-387. https://doi.org/10.1016/j.paid.2006.12.012

Shouhed, D., Beni, C., Manguso, N., IsHak, W. W., \& Gewertz, B. L. (2019). Association of emotional intelligence with malpractice claims: a review. JAMA surgery, 154(3), 250-256. doi:10.1001/ jamasurg.2018.5065

Trivellas, P., Gerogiannis, V., \& Svarna, S. (2013). Exploring workplace implications of Emotional Intelligence (WLEIS) in hospitals: Job satisfaction and turnover Intentions. ProcediaSocial and Behavioral Sciences, 73, 701-709. https://doi. org/10.1016/J.SBSPRO.2013.02.108

Weng, H. C., Chen, H. C., Chen, H. J., Lu, K., \& Hung, S. Y. (2008). Doctors' emotional intelligence and the patient-doctor relationship. Medical education, 42(7), 703-711. https://doi. org/10.1111/j.1365-2923.2008.03039.x

Wright, C, Richards, S. H., Hill, J. J., Roberts, M. J., Norman, G. R., Greco, M., Campbell, J. L. (2012). Multisource feedback in evaluating the performance of doctors: the example of the UK General Medical Council patient and colleague questionnaires. Academic Medicine, 87(12), 1668-1678. https://doi.org/10.1097/ ACM.0b013e3182724cc0

\section{AUTHOR CONTRIBUTION}

1. Syeda Shaista Waheed: Conception, writing and data analysis.

2. Tahir Siddique: Review of language references. 